\title{
A phosphorus/boron-containing triazine-trione derivative endowing epoxy resin with excellent flame retardance
}

\author{
H. J. Duan ${ }^{1}$, J. F. Cao ${ }^{1}$, Y. S. Chen ${ }^{1}$, J. S. Wang ${ }^{1}, S . J i^{1}$, H. R. Ma ${ }^{2 *}$ \\ ${ }^{1}$ School of Materials Science and Engineering, Wuhan University of Technology, 122 Luoshi Road, 430070 Wuhan, \\ China \\ ${ }^{2}$ Department of Chemistry, School of Chemistry, Chemical Engineering and Life Science, Wuhan University of \\ Technology, 122 Luoshi Road, 430070 Wuhan, China
}

Received 3 January 2020; accepted in revised form 9 March 2020

\begin{abstract}
A novel flame retardant containing boron and phosphorus, based on triazine-trione sturcture (TDB) was successfully synthesized, via substitution and esterification reaction between 1,3,5-tris(2-hydroxyethyl)isocyanurate (THEIC), diphenyl phosphoryl chloride (DPCP) and boric acid (BA), and then blended into DGEBA to prepare flame-retardant composites. The structure of TDB was characterized by Fourier transform infrared (FTIR) spectra and nuclear magnetic resonance (NMR). The thermal and flame-retardant properties of epoxy thermosets were systematically investigated. The results showed that the $T_{\mathrm{g}}, T_{5 \%}$ and $T_{\max }$ values of EP samples were gradually decreased with the increasing content of TDB, while the char yields at $700{ }^{\circ} \mathrm{C}$ increased. With the introduction of $10 \mathrm{wt} \% \mathrm{TDB}$, the LOI value of the thermoset was $27.5 \%$, and the UL-94 rating reached V-0. Furthermore, compared with pure EP, the peak heat release rate (pk-HRR) decreased by more than half, as well as the lower total heat release (THR) and total smoke production (TSP) were obtained. The flame retardant mechanism was studied by analyzing the char residue after cone calorimeter (CC) test and the pyrolysis products via scanning electronic microscopy (SEM), laser Raman spectroscopy (LRS), FTIR and Pyrolysis-gas chromatography/mass spectrometry (Py-GC/MS). It revealed that on account of the existence of triazine-trione structure and phosphorus/boron elements, the intumescent and compact phosphorus/boron-rich char layer was formed, meanwhile, the non-flammable gases and phosphorus-containing free radicals from triazine-trione and DPCP structure can develop the flame retardancy in the gas phase.
\end{abstract}

Keywords: polymer composites, epoxy resin, multielement flame retardant, borate, triazine-trione

\section{Introduction}

As a significant thermosetting resin, epoxy resin(EP) has been extensively used in various areas such as laminates, electronic insulators, coatings, adhesives, aerospace, etc., owing to its outstanding properties including excellent mechanical and electrical properties, good adhesive properties as well as great chemical and corrosion resistance, low curing shrinkage [1-6]. However, the high flammability, which is the intrinsic drawback of EP, restricts its application in some fields with high fire-resistant requirements
[7-8]. Therefore, it was meaningful to enhance the EPs' fire-resistance.

Traditionally, the halogen-containing flame retardant was selected due to its high flame-retardant efficiency, but it generates a considerable amount of toxic gas during combustion. Considering the health and ecosystem, the application of halogen-containing flame retardants was limited, while the halogen-free ones were developed rapidly in EPs, such as phosphorus [9-11], nitrogen [12], boron [13-15], sulfur [16], silicon [17]. Up to date, phosphorus-containing

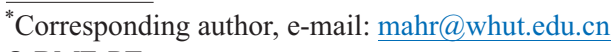

(C) BME-PT 
flame retardants play a significant role in improving the flame retardance of EPs; they can produce $\bullet P O$ and $\bullet \mathrm{HPO}$ radicals during combustion, which can capture $\cdot \mathrm{H}$ and $\bullet \mathrm{OH}$ radicals, as well as promoting the dehydration and carbonization of the polymer matrix and facilitating the formation of char layer [18], which can suppress further burning of the polymer matrix. Likewise, as an important component of halogenfree flame retardants, boron-containing flame retardant, such as zinc borate [19], can promote the formation of char layer and suppress the release of smoke during combustion, as well as the decomposition products are non-toxic, its flame retardant mechanism is as follows [20]: 1) When combusting, the zinc borate hydrate firstly dehydrates and absorbs part of the heat. Meanwhile, the removed water also dilutes the concentration of oxygen and flammable gas in the gas phase, which can suppress the combustion of the combustible gas; 2) In the condensed phase, a glassy protective layer is formed on the surface of the matrix to provide a sealing effect and promotes the formation of the char layer.

However, the flame retardants containing only one flame-retardant element can not satisfy the requirement in some fields, and the amount of addition is relatively large, which has a negative influence on the physical properties of the EP matrix. Therefore, multielement flame retardants have drawn much attention due to the synergistic effect among different elements, such as phosphorus/nitrogen [21-23], phosphorus/boron [24, 25], nitrogen/boron [26], phosphorus/nitrogen/silicon [27, 28], phosphorus/nitrogen/boron [29] systems. Based on these flame retardant systems, different structures containing functional groups have been used in some researches, such as phosphazene [30-32], Schiff base [33], triazine [34], maleimide [35], POSS [36], triazine-trione [37]. Among them, triazine and triazine-trione are excellent char-forming agents [38], which also have a positive effect in the gas phase. Tang et al. [39] synthesized a triazine-trione group-containing flame retardant (TAD) by using triallyl isocyanurate (TAIC) and DOPO. The results showed that with the introduction of TAD, the total smoke production (TSP) in cone calorimeter (CC) test had an obvious increase, especially the TSP of 10\%TAD/EP increased from $4022 \mathrm{~m}^{2} / \mathrm{m}^{2}$ of pure EP to $4888 \mathrm{~m}^{2} / \mathrm{m}^{2}$, which indicated TAD can not improve the flame retardant effect well in condensed phase. Therefore, for the sake of endowing the fire retardance of EP both in the condensed and gas phases, the triazine-trione structure is a good choice; meanwhile, the introduction of phosphorus, boron, and other elements such as silicon, sulfur can further develop the flame resistance of EP.

In this work, a novel flame retardant containing boron and phosphorus, based on triazine-trione sturcture (TDB) was successfully synthesized, via substitution and esterification reaction between 1,3,5-tris(2-hydroxyethyl)isocyanurate (THEIC), diphenyl phosphoryl chloride (DPCP) and boric acid (BA) and then blended it into epoxy resin to prepare the flameretardant EP composites. The chemical structure of TDB and the comprehensive properties of EP composites, including thermal stability, flame retardance, fire behavior, morphology, and flame retardant mechanism, were systematically investigated. The introduction of TDB developed the flame retardance of EP, especially the heat release rate, total heat release, and smoke production had a significant decrease. Due to the existence of triazine-trione structure and phosphorus/boron elements, the intumescent and compact carbon residue was obtained after burning.

\section{Materials and methods}

\subsection{Materials}

Diglycidyl ether of bisphenol A (DGEBA, E-51) was purchased from Yueyang Baling Huaxing Petrochemical Co., Ltd (Yueyang, China). Diphenyl phosphoryl chloride (DPCP) was supplied by Wuhan Yuancheng Technology Development Co., Ltd (Wuhan, China). 1,3,5-tris(2-hydroxyethyl)isocyanurate (THEIC) and 4,4'-diaminediphenyl sulfone (DDS) were provided by Guangdong Wengjiang Chemical Reagent Co., Ltd (Guangdong, China). Boric acid (BA) and $N, N^{\prime}-$ dimethylformamide (DMF) were purchased from Tianjin Beichen Founder Reagent Factory (Tianjin, China). Triethylamine was provided by Sinopharm Chemical Reagent Co., Ltd (Shanghai, China). 4-Dimethylaminopyridine (DMAP) was obtained by Shanghai Yusi Chemical Co., Ltd (Shanghai, China).

\subsection{Synthesis of TDB}

The synthetic route of TDB was shown in Figure 1. THEIC $(39.15 \mathrm{~g}, 0.15 \mathrm{~mol})$, triethylamine $(20.2 \mathrm{~g}$, $0.2 \mathrm{~mol})$, DMAP $(0.183 \mathrm{~g}, 0.0015 \mathrm{~mol})$ and $80 \mathrm{ml}$ DMF were orderly introduced into a $250 \mathrm{ml}$ threeneck flask equipped with a mechanical stirrer, thermometer, and reflux condenser. The mixture was stirred at room temperature until the homogeneous 


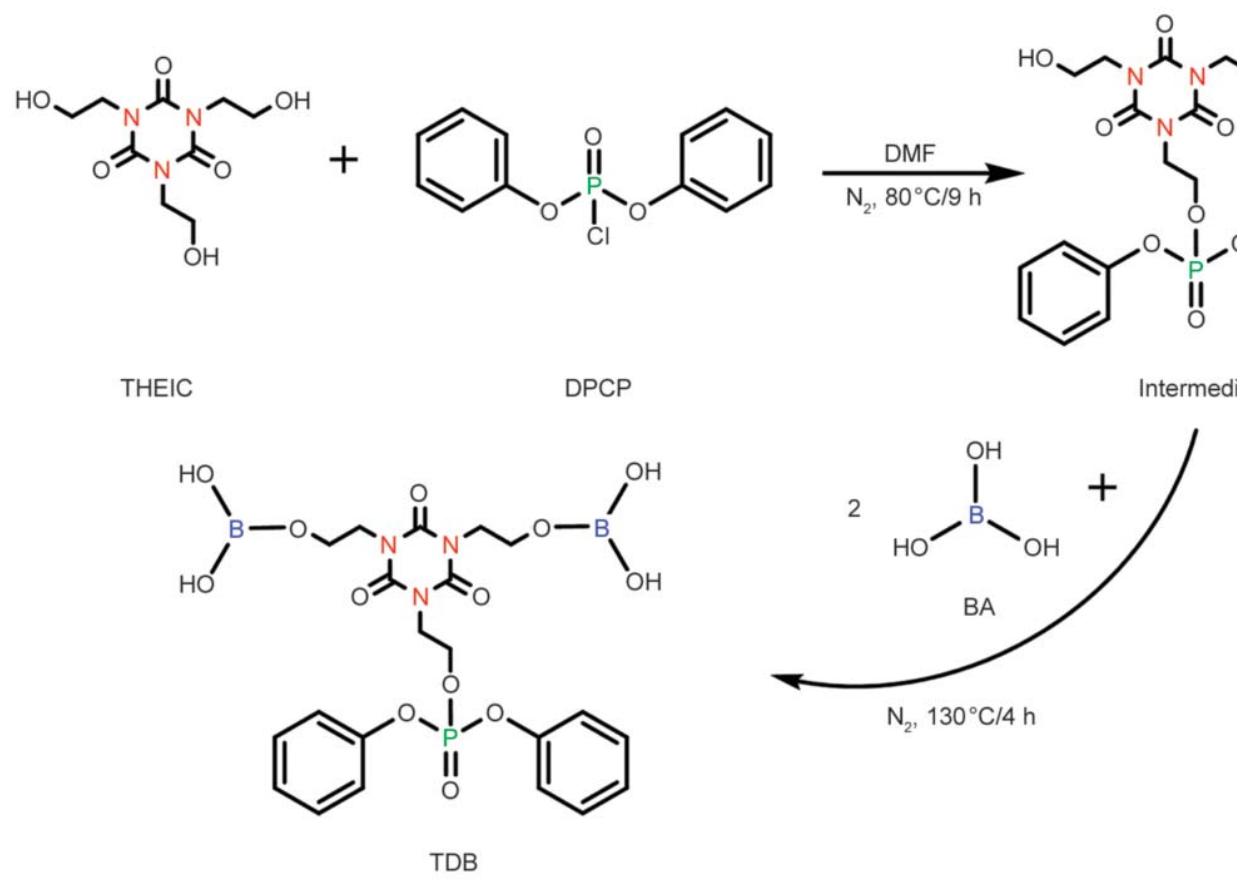

Figure 1. Synthetic route of TDB.

solution was obtained. Then DPCP (40.35 g, $0.15 \mathrm{~mol}$ ) dissolved in $40 \mathrm{ml}$ DMF was added dropwise over $2 \mathrm{~h}$ in an ice bath under nitrogen atmosphere. After that, the flask with the mixture was placed into an oil bath and heated to $80^{\circ} \mathrm{C}$, then maintained the temperature for $9 \mathrm{~h}$. After the reaction finished, the mixture was filtered to remove the triethylamine hydrochloride, and the filtrate was continued to participate in the subsequent reaction: boric acid (18.54 g, $0.3 \mathrm{~mol})$ was incorporated into the filtrate under $\mathrm{N}_{2}$ atmosphere, and the mixture was heated to $130^{\circ} \mathrm{C}$, kept for $4 \mathrm{~h}$. After the reaction was completed, the mixture was distilled to remove DMF, and the brown viscous liquid was collected. Then the product was washed by deionized water and vacuum-dried at $80^{\circ} \mathrm{C}$ for $24 \mathrm{~h}$. The yield of TDB was $82 \%$.

\subsection{Preparation of flame-retardant EP samples}

All the EP samples were prepared via the traditional curing process, and the formulations of all samples were presented in Table 1 with calculated phosphorus, nitrogen, and boron contents. The detailed preparation process was as follows: TDB was introduced into E-51 and stirred at $120^{\circ} \mathrm{C}$ until a homogeneous solution was obtained. Then, DDS was added in a stoichiometric amount relative to EP and thoroughly blended in order to get a homogeneous solution. Afterward, the mixture was degassed under vacuum for 5 min until bubbles were entirely removed. The mixture was poured into a preheated mold and cured at $120^{\circ} \mathrm{C}$ for $2 \mathrm{~h}, 140^{\circ} \mathrm{C}$ for $2 \mathrm{~h}$, and postcured at $160^{\circ} \mathrm{C}$ for $4 \mathrm{~h}$. The neat EP samples were prepared by a similar procedure but without the addition of TDB.

\subsection{Characterization}

Fourier Transform Infrared (FTIR) spectra were recorded using a Nicolet 6700 infrared spectrometer (Thermo Electron Scientific Instruments, Madison, WI, USA) in the range of $4000-400 \mathrm{~cm}^{-1}$. The samples were mixed with $\mathrm{KBr}$ and pressed into pellets before characterization.

Table 1. Formulations of EP samples.

\begin{tabular}{|c|c|c|c|c|c|c|}
\hline Sample & $\begin{array}{c}\text { E-51 } \\
{[g]}\end{array}$ & $\begin{array}{c}\text { TDB } \\
{[\mathrm{g}]}\end{array}$ & $\begin{array}{c}\text { DDS } \\
{[\mathrm{g}]}\end{array}$ & $\begin{array}{c}P \text { content } \\
\text { [wt } \%]\end{array}$ & $\begin{array}{c}\mathbf{N} \text { content } \\
\text { [wt } \%]\end{array}$ & $\begin{array}{c}\text { B content } \\
{[w t \%]}\end{array}$ \\
\hline EP & 80 & 0 & 25.30 & 0 & 0.03 & 0 \\
\hline $\mathrm{EP} / 5 \mathrm{wt} \% \mathrm{TDB}$ & 80 & 5.54 & 25.30 & 0.27 & 0.39 & 0.19 \\
\hline $\mathrm{EP} / 7.5 \mathrm{wt} \% \mathrm{TDB}$ & 80 & 8.54 & 25.30 & 0.40 & 0.57 & 0.28 \\
\hline $\mathrm{EP} / 10 \mathrm{wt} \% \mathrm{TDB}$ & 80 & 11.70 & 25.30 & 0.53 & 0.74 & 0.37 \\
\hline
\end{tabular}


${ }^{1} \mathrm{H}$ NMR and ${ }^{31} \mathrm{P}$ NMR spectra were measured with a Bruker AV400 NMR spectrometer (Bruker, Fällanden, Switzerland) using DMSO- $d_{6}$ as the solvent. Thermogravimetric analysis (TGA) was performed using a NETZSCH STA449F3 (NETZSCH, Selb, Germany) at a heating rate of $10^{\circ} \mathrm{C} / \mathrm{min}$ from 40 to $700^{\circ} \mathrm{C}$ in an air atmosphere.

The limited oxygen index (LOI) values were obtained using a JF-3 oxygen index meter (Jiangning Analysis Instrument Company, Jiangning, China) according to ASTM D2863 and the sheet dimensions of samples were $100 \times 6.5 \times 3 \mathrm{~mm}^{3}$.

Vertical burning (UL-94) tests were evaluated on NK8017A instrument (Nklsky Instrument Co., Ltd, China) with a dimension of $130 \times 13 \times 3 \mathrm{~mm}^{3}$ according to ASTM D3801.

The cone calorimeter (CC) measurements were performed to evaluate the fire behavior by using a FTT cone calorimeter (Motis Fire Technology Co., Ltd, Kunshan, China) according to the ISO 5660-1 standard at an external heat flux of $50 \mathrm{~kW} / \mathrm{m}^{2}$. The dimensions of all samples were $100 \times 100 \times 3 \mathrm{~mm}^{3}$.

Dynamic mechanical analysis (DMA) was tested on Pyris Diamond dynamic thermal mechanical analyzer (PE, Waltham, Massachusetts, USA). The samples with the dimension of $40 \times 10 \times 3 \mathrm{~mm}^{3}$ were tested in bending mode at a heating rate of $5^{\circ} \mathrm{C} / \mathrm{min}$ and a constant frequency of $1 \mathrm{~Hz}$.

Scanning electronic microscopy (SEM) was employed to analyze the surface morphology of the char residue after cone calorimeter by using a Hitachi S4800 scanning electron microscope (Hitachi, Tokyo, Japan).

Laser Raman spectroscopy (LRS) measurements were implemented via an InVia laser Raman spectrometer (RENISHAW, Gloucestershire, Britain) with the excitation wavelength of $633 \mathrm{~nm}$.

Pyrolysis-gas chromatography/mass spectrometry (Py-GC/MS) was implemented with an Agilent 7890/5975 GC/MS (Agilent Technologies Inc., California, USA). The injector temperature was $250^{\circ} \mathrm{C}$, $1 \mathrm{~min}$ at $50^{\circ} \mathrm{C}$; then the temperature was increased to $280^{\circ} \mathrm{C}$ at a rate of $8^{\circ} \mathrm{C} / \mathrm{min}$. The temperature of the $\mathrm{GC} / \mathrm{MS}$ interface was $280^{\circ} \mathrm{C}$, and the pyrolysis temperature was $500^{\circ} \mathrm{C}$.

\section{Results and discussion}

\subsection{Structure characterization of TDB}

The chemical structure of TDB was characterized by means of FTIR, ${ }^{1} \mathrm{H}$ NMR, and ${ }^{31} \mathrm{P}$ NMR. The FTIR

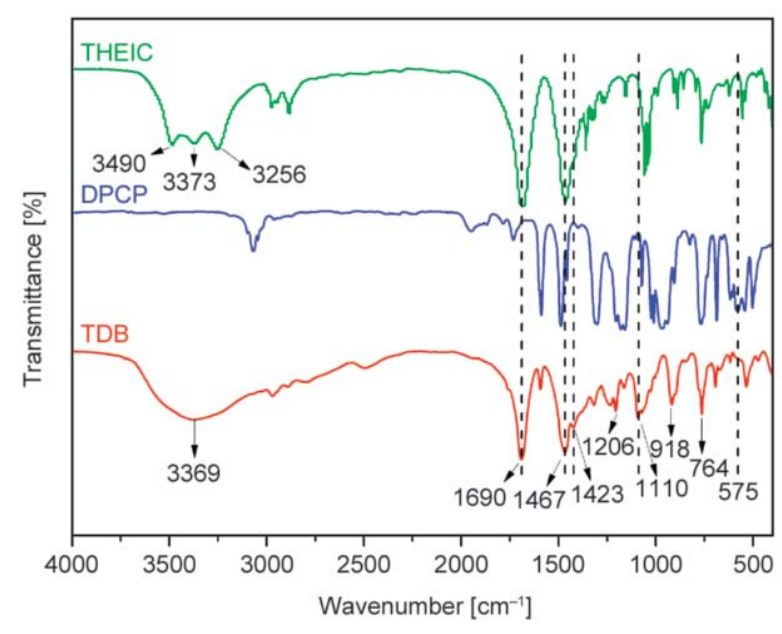

Figure 2. FTIR spectra of THEIC, DPCP and TDB.

spectra of THEIC, DPCP, and TDB were exhibited in Figure 2. Comparing the FTIR spectrum of TDB and DPCP, it was obvious that the peak at $575 \mathrm{~cm}^{-1}$ belonged to the typical absorption peak of $\mathrm{P}-\mathrm{Cl}$, while it disappeared in the spectrum of TDB, which indicated the successful reaction between DPCP and THEIC. In addition, the absorption peaks at 764 and $918 \mathrm{~cm}^{-1}$ were assigned to the typical absorption peaks of P-O-Ph derived from DPCP, as well as the absorption peaks at 1206 and $1110 \mathrm{~cm}^{-1}$ were due to the stretching vibration of $\mathrm{P}=\mathrm{O}[40]$ and $\mathrm{P}-\mathrm{O}-\mathrm{C}$ [41], which can further prove the reaction between DPCP and THEIC. The peaks at 1690 and $1467 \mathrm{~cm}^{-1}$ were attributed to the stretching vibrations of $\mathrm{C}=\mathrm{O}$ and $\mathrm{C}-\mathrm{N}$, respectively, which indicated the existence of triazine-trione group derived from THEIC. Furthermore, in the FTIR spectrum of THEIC, the peaks at 3490,3373 , and $3256 \mathrm{~cm}^{-1}$ were assigned to the stretching vibration of $\mathrm{O}-\mathrm{H}$, while the single peak of $\mathrm{O}-\mathrm{H}$ at $3369 \mathrm{~cm}^{-1}$ appeared in the spectrum of TDB and the existence of the typical absorption peak of B-O-C at $1423 \mathrm{~cm}^{-1}$ [29] can be the evidence of the reaction between THEIC and boric acid.

The ${ }^{1} \mathrm{H}$ NMR (a) and ${ }^{31} \mathrm{P}$ NMR (b) spectra of TDB were shown in Figure 3. In the ${ }^{1} \mathrm{H}$ NMR spectrum of TDB, the peaks at $6.97-7.35 \mathrm{ppm}$ were assigned to the proton of benzene $\operatorname{ring}\left(\mathrm{H}^{\mathrm{a}}\right)$; the peaks at 2.70 $2.9 \mathrm{ppm}$ were attributed to the methylene connected with the DPCP group $\left(\mathrm{H}^{\mathrm{b}}\right)$; the peaks at 2.42-2.49, 3.51-3.58, and 3.82-3.87 ppm belonged to the methylene connected to the triazine-trione group $\left(\mathrm{H}^{\mathrm{c}}\right)$ $\left(\mathrm{H}^{\mathrm{d}}\right)$ and the boric acid groups $\left(\mathrm{H}^{\mathrm{e}}\right)$, respectively. Moreover, the peak at 7.95-8.15 ppm was attributed to the proton of $\mathrm{O}-\mathrm{H}$ derived from boric acid $\left(\mathrm{H}^{\mathrm{f}}\right)$. As is shown in the ${ }^{31} \mathrm{P}$ NMR of TDB, there was only 


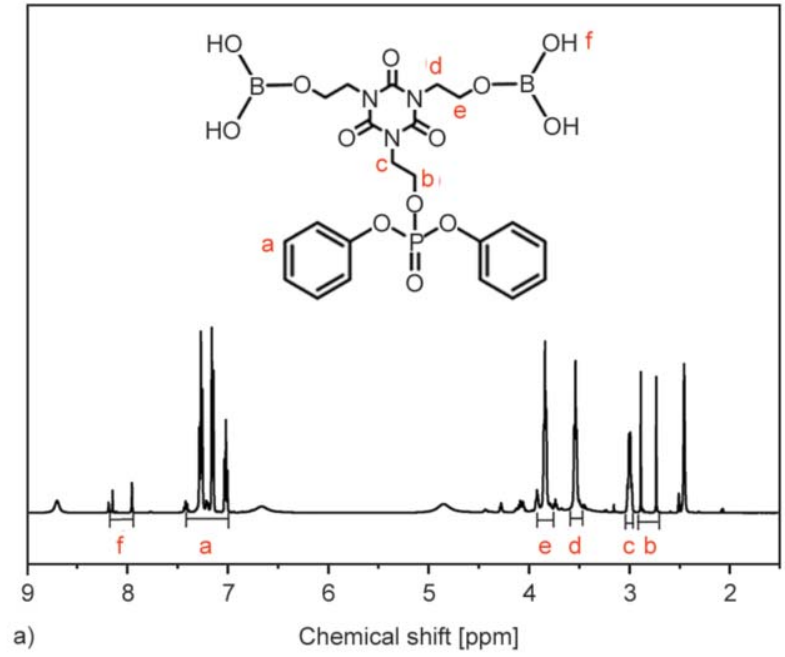

Figure 3. ${ }^{1} \mathrm{H}$ NMR (a) and ${ }^{31} \mathrm{P}$ NMR (b) spectra of TDB.

one signal located at $-11.38 \mathrm{ppm}$, which derived from DPCP group. All information mentioned above confirmed that TDB was successfully synthesized.

\subsection{The compatibility between TDB and epoxy resin}

The compatibility of flame retardant with the epoxy resin determined whether the flame retardant can be uniformly dispersed in the epoxy resin, thereby influencing the physical and chemical properties of the epoxy resin. The compatibility of TDB with EP was analyzed from the optical photo of each sample. As shown in Figure 4, when the amounts of TDB were $5,7.5$, and $10 \mathrm{wt} \%$, respectively, there were various
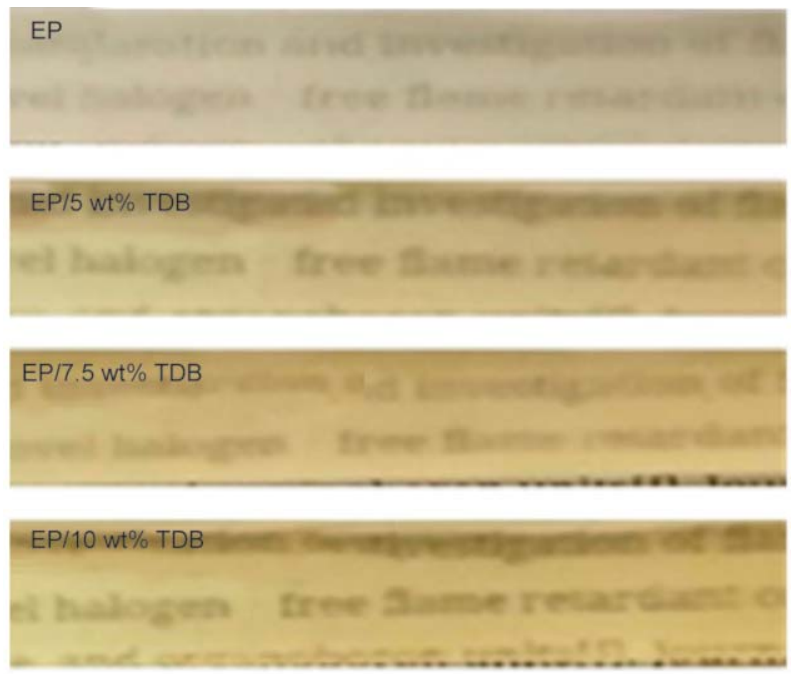

$E P / 12.5 w t \%$ TDB

Figure 4. The optical photos of EP thermosets.

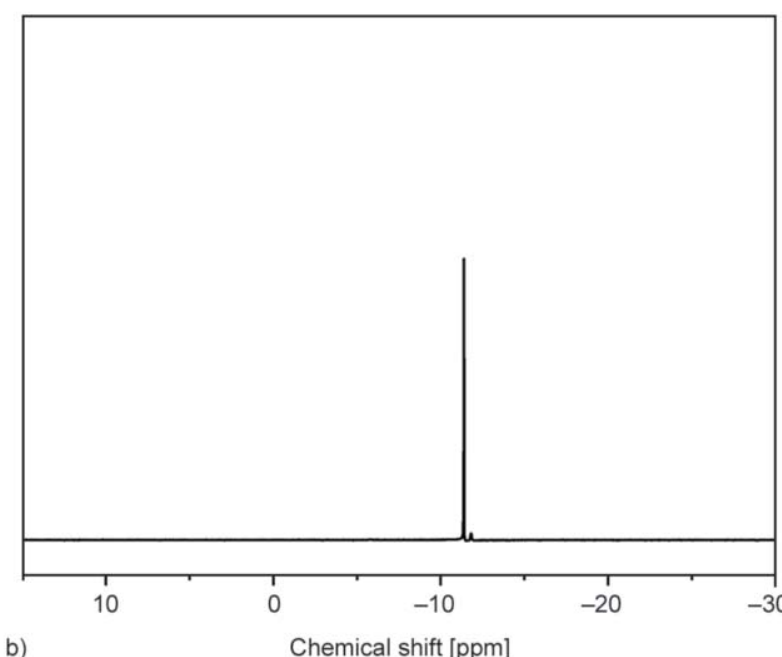

degrees of transparency that appeared in different EP samples, manifesting good compatibility of TDB with epoxy resin. And as the amount of TDB increased, the color of EP samples became darker. However, the amount of TDB was increased to $12.5 \mathrm{wt} \%$; the transparency of the sample got worse, accompanied by small bubbles existed in the EP sample, which indicated that excess addition of TDB had an obvious influence on compatibility between TDB and epoxy resin. It was well-known that a large amount of additive flame retardant may precipitate when added into epoxy resin, worsening the compatibility with epoxy resin. Therefore, the flame-retardant EP may have good comprehensive performance, even though the maximum added amount was controlled to be about $10 \mathrm{wt} \%$.

\subsection{Thermal properties of EP thermosets}

The glass transition temperature $\left(T_{\mathrm{g}}\right)$, as was wellknown, was one of the significant parameters used to measure the thermal properties of EP thermosets [42]. DMA was employed to record the $T_{\mathrm{g}}$ and the storage modulus $\left(E^{\prime}\right)$ of all EP samples, the corresponding DMA curves were shown in Figure 5, and the relevant data were presented in Table 2. From Figure $5 b$, it was seen that there was a single peak in all tan delta curves, indicating good compatibility between TDB and epoxy resin, which was consistent with the result of the optical photos. In order to explain the influence on $T_{\mathrm{g}}$ with the introduction of TDB, the crosslinking density $\left(v_{\mathrm{e}}\right)$ was adopted [43], which was calculated using the rubber elasticity Equation (1): 

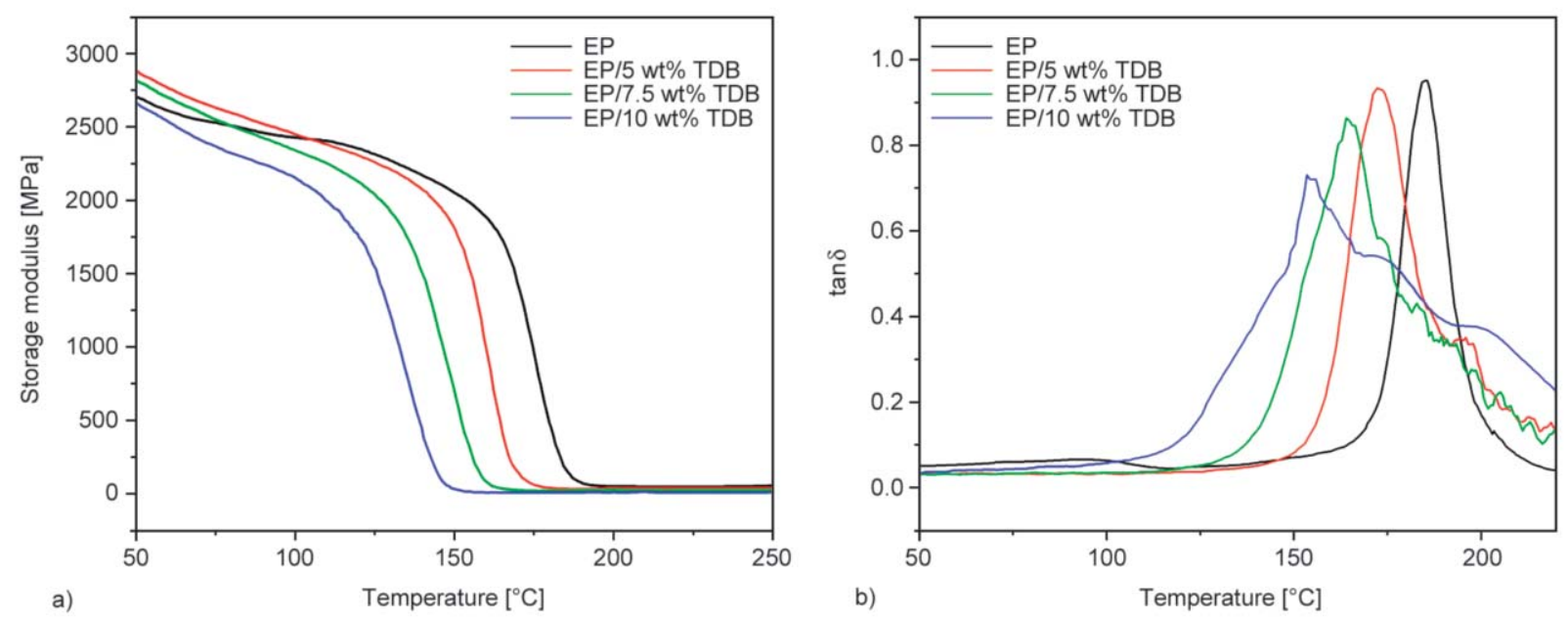

Figure 5. DMA curves of EP thermosets containing different content of TDB: a) storage modulus $\left.\left(E^{\prime}\right), \mathrm{b}\right) \tan \delta$.

Table 2. DMA results of EP samples.

\begin{tabular}{|l|c|c|c|c|}
\hline \multicolumn{1}{|c|}{ Sample } & $\begin{array}{c}\boldsymbol{T}_{\mathbf{g}} \\
{\left[{ }^{\circ} \mathbf{C}\right]}\end{array}$ & $\begin{array}{c}\boldsymbol{E}^{\prime} \text { at } \mathbf{5 0}{ }^{\circ} \mathbf{C} \\
{[\mathbf{M P a}]}\end{array}$ & $\begin{array}{c}\boldsymbol{E}^{\prime} \text { at } \boldsymbol{T}_{\mathbf{g}}+\mathbf{4 0}^{\circ} \mathbf{C} \\
{[\mathbf{M P a}]}\end{array}$ & $\begin{array}{c}\boldsymbol{v}_{\mathbf{e}} \\
{\left[\mathbf{m o l} / \mathbf{m}^{3}\right]}\end{array}$ \\
\hline EP & 184 & 2711 & 47.3 & 3814 \\
\hline EP/5 $\mathrm{wt} \% \mathrm{TDB}$ & 173 & 2882 & 39.5 & 3274 \\
\hline $\mathrm{EP} / 7.5 \mathrm{wt} \% \mathrm{TDB}$ & 165 & 2814 & 23.7 & 1987 \\
\hline $\mathrm{EP} / 10 \mathrm{wt} \% \mathrm{TDB}$ & 153 & 2656 & 10.0 & 860 \\
\hline
\end{tabular}

$v_{\mathrm{e}}=\frac{E^{\prime}}{3 R T}$

where $E^{\prime}$ is the storage modulus at $T_{\mathrm{g}}+40^{\circ} \mathrm{C}$ in the rubbery plateau, $R$ is the gas constant, and $T$ is the absolute temperature of $T_{\mathrm{g}}+40^{\circ} \mathrm{C}$. As shown in Table 2, the ve of flame-retardant EP thermosets gradually decreased with the content of TDB increased, leading to a decrease of $T_{\mathrm{g}}$. It was worth noting that $\mathrm{EP} / 7.5 \mathrm{wt} \% \mathrm{TDB}$ had the $T_{\mathrm{g}}$ value of $165^{\circ} \mathrm{C}$, with a little reduction of $10.3 \%$, even though the addition of TDB increased to $10 \mathrm{wt} \%$, the reduction had a small increase to $16.8 \%$. The decline of $T_{\mathrm{g}}$ was because that TDB was used as an additive flame retardant, the steric hindrance caused by the bulky molecular structure reduced the crosslinking density of epoxy networks, although the rigid groups from DPCP group were introduced, it can not offset the great influence on crosslinking density. Furthermore, it can be seen that $\mathrm{EP} / 5 \mathrm{wt} \% \mathrm{TDB}$ and $\mathrm{EP} / 7.5 \mathrm{wt} \%$ TDB have a little higher $E^{\prime}$ than EP at $50^{\circ} \mathrm{C}$, which was attributed to the introduction of rigid groups, however, with the increasing amount of TDB, the ve decreased, indicating the decline of rigidity, which caused the little decrease of $E^{\prime}$.

In order to evaluate the influence of TDB on the thermal stability of epoxy resin, TGA was studied in air, the corresponding TG and DTG curves were shown in Figure 6, as well as the relevant data, were presented in Table 3, including the initial decomposition temperature $\left(T_{5 \%}\right)$, defined as $5 \%$ weight loss temperature, the maximum weight loss temperature $\left(T_{\max }\right)$, defined as the temperature at the maximum mass loss rate, the maximum decomposition rate $\left(R_{\max }\right)$ as well as the char residue at $700^{\circ} \mathrm{C}$. From Figure 6, it can be seen that TDB and all the EP samples exhibited a two-step decomposition process, the first decomposition stage occurred about 250 to $400{ }^{\circ} \mathrm{C}$,

Table 3. Thermal stability parameters of EP thermosets.

\begin{tabular}{|c|c|c|c|c|c|c|}
\hline Sample & $\begin{array}{l}T_{5 \%} \\
{\left[{ }^{\circ} \mathrm{C}\right]}\end{array}$ & $\begin{array}{l}T_{\max 1} \\
{\left[{ }^{\circ} \mathbf{C}\right]}\end{array}$ & $\begin{array}{l}T_{\max 2} \\
{\left[{ }^{\circ} \mathrm{C}\right]}\end{array}$ & $\begin{array}{c}R_{\max 1} \\
{[\% / \min ]}\end{array}$ & $\begin{array}{c}R_{\max 2} \\
{[\% / \min ]}\end{array}$ & $\begin{array}{c}\text { Char residue at } 700^{\circ} \mathrm{C} \\
{[\%]}\end{array}$ \\
\hline TDB & 306.2 & 345.2 & 548.9 & 8.44 & 3.92 & 4.98 \\
\hline EP & 303.4 & 340.2 & 557.0 & 4.52 & 4.63 & 0 \\
\hline $\mathrm{EP} / 5 \mathrm{wt} \% \mathrm{TDB}$ & 302.2 & 338.0 & 551.5 & 3.84 & 4.96 & 0.33 \\
\hline $\mathrm{EP} / 7.5 \mathrm{wt} \% \mathrm{TDB}$ & 293.8 & 336.1 & 550.1 & 3.68 & 4.95 & 1.88 \\
\hline $\mathrm{EP} / 10 \mathrm{wt} \% \mathrm{TDB}$ & 289.7 & 335.6 & 552.8 & 3.36 & 4.54 & 6.05 \\
\hline
\end{tabular}



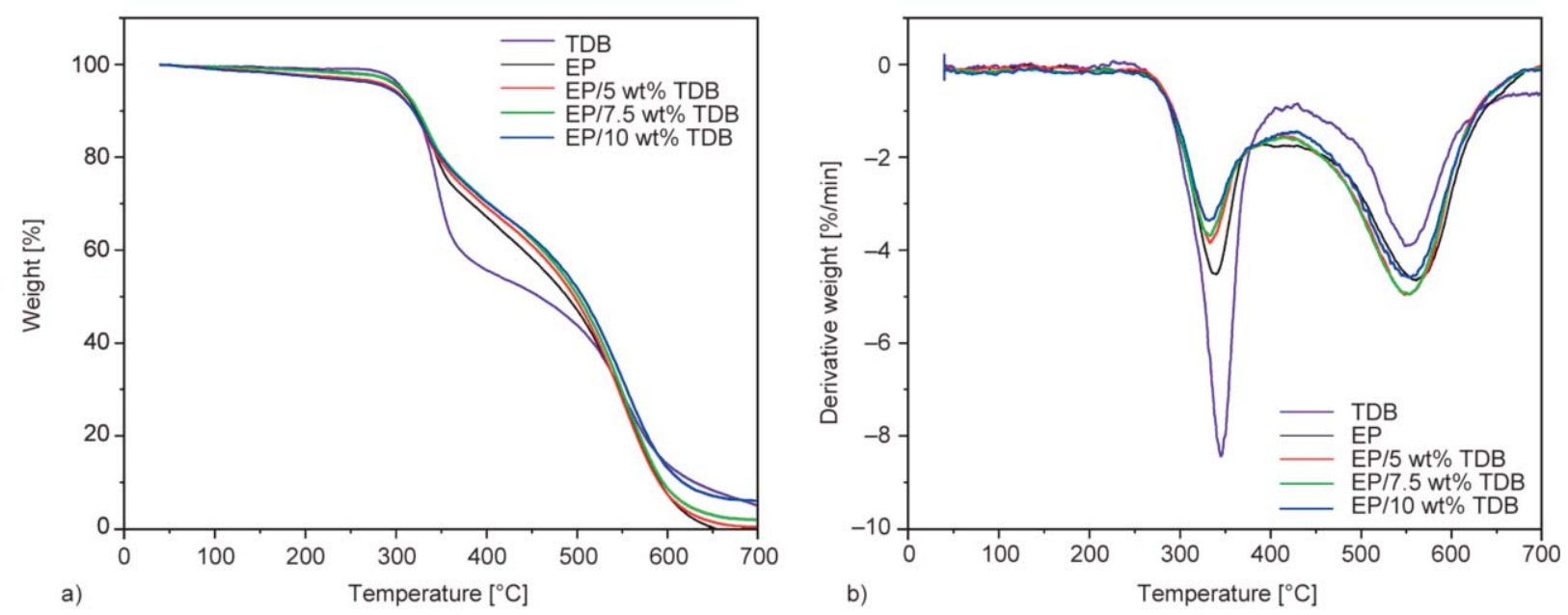

Figure 6. TG (a) and DTG (b) curves of TDB and EP thermosets under air atmosphere.

corresponding to the decomposition of epoxy resin molecular chain and the flame retardant; the second decomposition state appeared approximately 450 to $650^{\circ} \mathrm{C}$, corresponding to the further oxidative degradation of the epoxy resin matrix. As for TDB, the first stage was ascribed to the decomposition of DPCP group, while the second stage belonged to the degradation of triazine-trione group. The decomposition process of TDB will be further investigated. In addition, with the additive amount of TDB increasing, the $T_{5 \%}$ of the flame-retardant EP samples had a small decrease from 303.4 to $289.7^{\circ} \mathrm{C}$. Similarly, the $T_{\max }$ (including $T_{\max 1}$ and $T_{\max 2}$ ) of the flame-retardant EP samples shifted to the lower temperature. The declinations indicated the earlier decomposition of flameretardant EP samples, which was attributed to the catalytic decomposition effect of TDB. It was worth noting that the decrease of $T_{5 \%}$ and $T_{\max }$ was not obvious, suggesting the little influence on the thermal stability of EP. Furthermore, the char yields at $700^{\circ} \mathrm{C}$ of the flame-retardant EP samples were gradually increased from no residual for pure EP to $6.05 \%$ for $\mathrm{EP} / 10 \mathrm{wt} \% \mathrm{TDB}$, which suggested that the introduction of TDB can promote the char formation of the flame-retardant EP composites to some extent.

As can be seen from Figure 6b, in the first decomposition stage, the addition of TDB can significantly reduce the weight loss rate of the epoxy resin, and as the content of TDB increased, the weight loss rate was further reduced. The reason for the result was that the flame retardant could generate radical scavenger during the decomposition process, leading to the slow decomposition of the epoxy resin molecular chain. However, in the second decomposition process, the inhibitory effect of the flame retardant on the epoxy resin was not obvious, and only when the addition amount of TDB was $10 \mathrm{wt} \%$, the weak inhibition was exhibited. This result was mainly attributed to that when the additive amount of TDB was low, the content of phosphorus and boron in the epoxy resin system was low accordingly; thus, the effect of char formation was not obvious, that is the thermal oxidation of EP matrix can not be restrained well.

\subsection{Flame retardancy of EP thermosets}

The flame retardance of all EP samples was assessed by LOI and UL-94 tests, and the corresponding results were listed in Table 4. It was shown that the pure EP sample had an LOI value of only $22.2 \%$ and failed to pass the UL-94 test, implying the inflammability of EP. With the addition of TDB, the LOI values of EP samples increased, indicating the improvement of flame retardancy of EP samples. The LOI value of EP/TDB composites increased to $26.8 \%$ with $5 \mathrm{wt} \%$ TDB was loaded, and a vertical UL-94 $\mathrm{V}-1$ rating was obtained. When the content of TDB enhanced to $7.5 \mathrm{wt} \%$, the highest LOI value of $28.3 \%$ was acquired, accompanied by the same UL-94 V-1 rating. The content of TDB continued to raise to $10 \mathrm{wt} \%$, the UL-94 rating reached to V-0, while the LOI had a lower value of $27.5 \%$ compared with $\mathrm{EP} / 7.5 \mathrm{wt} \% \mathrm{TDB}$ sample, it was attributed to that much gases released from the matrix during combustion, which destroyed the char layer, leading to the lower LOI value. Figure 7 showed the pictures of neat EP and EP/TDB samples after LOI tests. It was obvious that the neat EP had less residue after burning. With the increase of TDB content, the more residue was left, and the expanded char layer was obtained. That was to say, the introduction of TDB 
Table 4. LOI values and UL 94 ratings of EP thermosets.

\begin{tabular}{|l|c|c|c|}
\hline \multicolumn{1}{|c|}{ Sample } & $\begin{array}{c}\text { LOI } \\
{[\%]}\end{array}$ & UL 94 (3 mm) & Dripping \\
\hline $\mathrm{EP}$ & 22.2 & No Rating & Yes \\
\hline $\mathrm{EP} / 5 \mathrm{wt} \% \mathrm{TDB}$ & 26.8 & $\mathrm{~V}-1$ & No \\
\hline $\mathrm{EP} / 7.5 \mathrm{wt} \% \mathrm{TDB}$ & 28.3 & $\mathrm{~V}-1$ & No \\
\hline $\mathrm{EP} / 10 \mathrm{wt} \% \mathrm{TDB}$ & 27.5 & $\mathrm{~V}-0$ & No \\
\hline
\end{tabular}
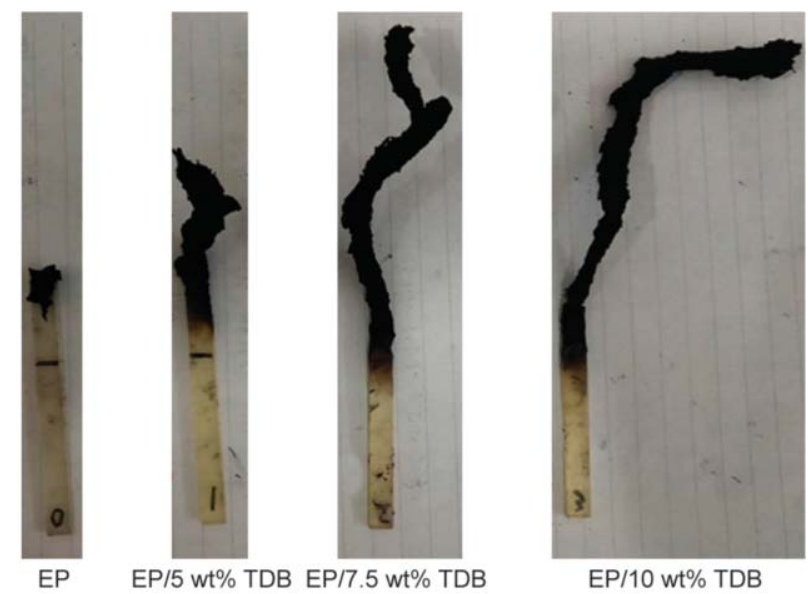

Figure 7. Pictures of EP thermosets after LOI tests.

could extend the char layer, isolate the oxygen, and restrain the heat exchange, which helped in preventing the drip of EP composites. Additionally, the reason for the lower LOI value of EP/10 wt $\%$ TDB sample may be that the char layer was quickly destroyed by the increased release of gases, which receded the flame-retardant effect of TDB.

\subsection{Fire behavior analyses of EP thermosets}

In order to further analyze the different fire behaviors of pure EP and EP/TDB composites, the cone calorimeter test was employed, owing to its test environment similar to the real burning situation, and the obtained test data can evaluate the burning behavior of the material in the fire [44]. Figure 8 showed the curves of heat release rate (HRR), total heat release (THR), smoke production rate (SPR), and total smoke production (TSP) as a function of time. The corresponding data were listed in Table 5, in addition to these, the time to ignition (TTI), average yield of $\mathrm{CO}$ (av-COY), average yield of $\mathrm{CO}_{2}\left(\mathrm{av}-\mathrm{CO}_{2} \mathrm{Y}\right)$, fire growth index (FGI), the averaged effective heat of combustion (av-EHC) and residue char yield at $400 \mathrm{~s}$ were also summarized.

From Table 5 we can see that the TTI value of pure EP was $73 \mathrm{~s}$. With the flame retardant incorporated, all the EP/TDB composites had lower TTI values, which can be put down to the catalytic decomposition of TDB, leading to the weaker resistance of EP matrix to ignition.

The HRR was the most significant performance parameter to assess the fire intensity. As shown in Figure 8a, the pure EP burnt fiercely after kindled, and the peak heat release rate (pk-HRR) of $1022.0 \mathrm{~kW} / \mathrm{m}^{2}$ was obtained. While TDB was introduced, the pkHRR of EP/TDB composites decreased rapidly, especially $\mathrm{EP} / 10 \mathrm{wt} \% \mathrm{TDB}$, had a minimum value of $483.8 \mathrm{~kW} / \mathrm{m}^{2}$, which decreased by $52.7 \%$. In like manner, the THR of all the EP/TDB composites had obvious reduction compared to pure EP, from 81.5 to $56.7 \mathrm{MJ} / \mathrm{m}^{2}$, corresponding to a $30.4 \%$ reduction. The above results can be attributed to the barrier effect and quenching effect, on the one hand, due to the early decomposition of TDB, some pyrolysis products, such as phosphates, promoted the formation of char layers, which can block the exchange of heat and oxygen between EP matrix and external environment; on the other hand, the phosphorous free radicals generated from pyrolysis process can capture $\cdot \mathrm{H}$ and $\bullet \mathrm{OH}$ radicals, leading to the termination of burning reaction.

Table 5. Cone calorimeter test results of EP thermosets.

\begin{tabular}{|ll|c|c|c|c|}
\hline \multicolumn{2}{|c|}{ Samples } & EP & EP/5 wt\% TDB & EP/7.5 wt\% TDB & EP/10 wt\% TDB \\
\hline TTI & {$[\mathrm{s}]$} & 73 & 54 & 51 & 50 \\
\hline pk-HRR & {$\left[\mathrm{kW} / \mathrm{m}^{2}\right]$} & 1022.0 & 674.4 & 550.9 & 483.8 \\
\hline THR & {$\left[\mathrm{MJ} / \mathrm{m}^{2}\right]$} & 81.5 & 66.1 & 62.8 & 56.7 \\
\hline pk-SPR & {$\left[\mathrm{m}^{2} / \mathrm{s}\right]$} & 0.158 & 0.137 & 0.124 & 0.109 \\
\hline TSP & {$\left[\mathrm{m}^{2}\right]$} & 17.3 & 14.0 & 13.1 & 12.3 \\
\hline av-COY & {$[\mathrm{kg} / \mathrm{kg}]$} & 0.068 & 0.071 & 0.073 & 1.653 \\
\hline av-CO2Y & {$[\mathrm{kg} / \mathrm{kg}]$} & 1.871 & 1.740 & 16.9 & 16.1 \\
\hline av-EHC & {$[\mathrm{MJ} / \mathrm{kg}]$} & 21.8 & 18.7 & 164 & 178 \\
\hline Tp & {$[\mathrm{s}]$} & 152 & 147 & 3.4 & 2.7 \\
\hline FGI & {$\left[\mathrm{kW} /\left(\mathrm{m}^{2} \cdot \mathrm{s}\right)\right]$} & 6.7 & 4.6 & 23.48 & 30.37 \\
\hline Residue & {$[\%]$} & 5.23 & 20.12 & & \\
\hline
\end{tabular}



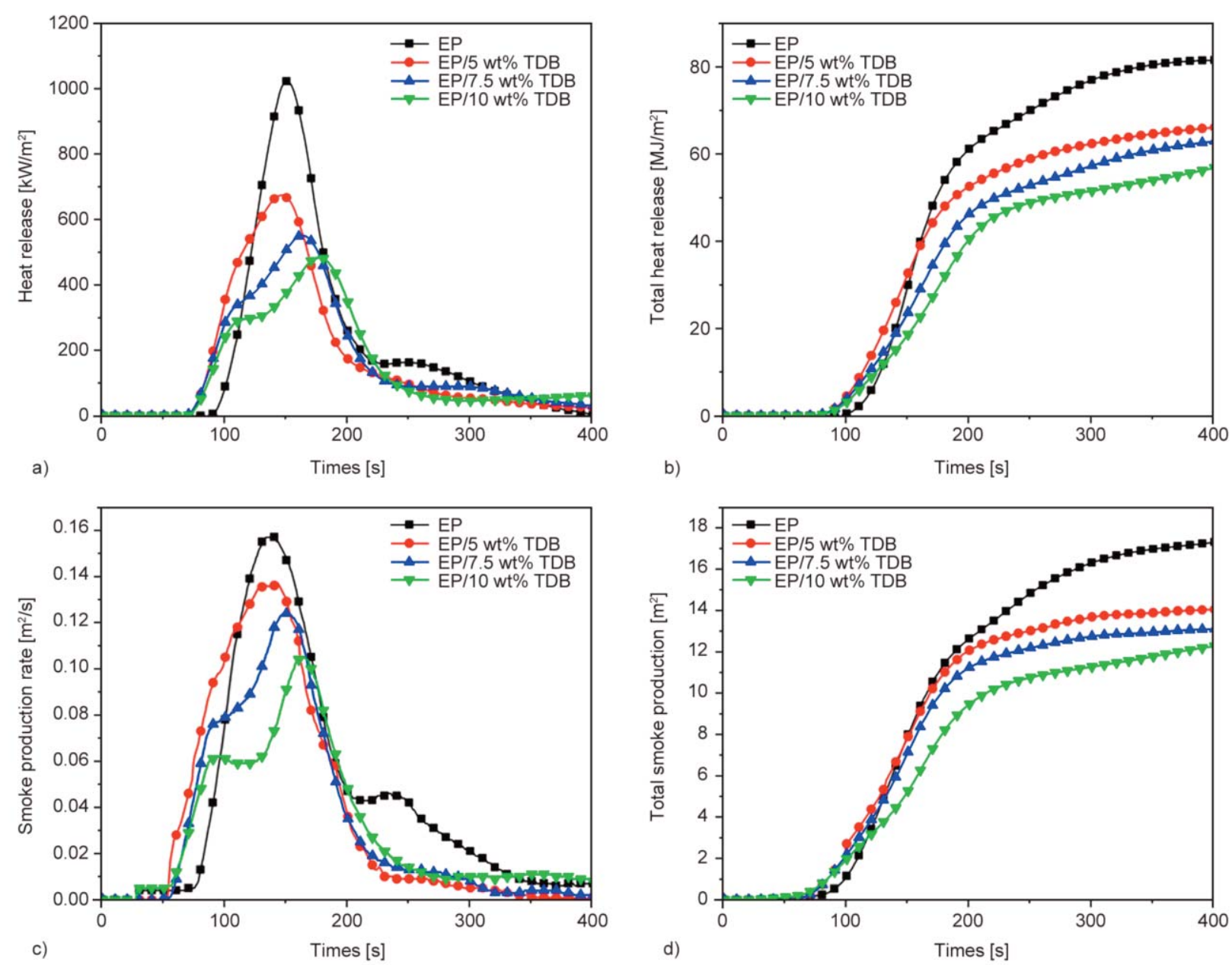

Figure 8. HRR (a), THR (b), SPR (c), and TSP (d) curves of EP thermosets containing different content of TDB.

As shown in Table 5, the pk-SPR of pure EP was $0.158 \mathrm{~m}^{2} / \mathrm{s}$, while EP/TDB composites had lower pk-SPR with the additional amount of TDB increased. Compared to pure EP, EP/10 wt \% TDB thermoset had the lowest value of $0.109 \mathrm{~m}^{2} / \mathrm{s}$, decreased by $31.0 \%$. Besides, the TSP of EP/10 wt $\%$ TDB thermoset reduced to $12.25 \mathrm{~m}^{2}$, compared with $17.3 \mathrm{~m}^{2}$ of pure EP's TSP value, which decreased by $29.2 \%$. The results confirmed that the addition of TDB could effectively improve the smoke suppression performance of EP matrix.

In the real fire hazard, many materials released many poison gases during a fire, which had great harm to human health; therefore, the content of toxic gases was also a significant parameter in the CC test. In Table 5, the av-COY of pure EP was $0.068 \mathrm{~kg} / \mathrm{kg}$, while all the EP/TDB composites had a higher av$\mathrm{COY}$ value. On the contrary, the av-CO2Y of pure EP was $1.871 \mathrm{~kg} / \mathrm{kg}$, while all the EP/TDB composites had a lower av- $\mathrm{CO}_{2} \mathrm{Y}$ value. The reason for the results was the incomplete burning of EP matrix; that is, the formed char layer prevented the EP matrix from further oxidation. Furthermore, the FGI in Table 5 defined as the ratio of pk-HRR to time to peak $\left(T_{\mathrm{p}}\right)$; the lower the FGI value was, the slower the fire grew, the more time people had to escape from the fire hazard. The FGI of pure EP was $6.7 \mathrm{~kW} /\left(\mathrm{m}^{2} \cdot \mathrm{s}\right)$, with the TDB content increased, the EP/TDB composites had lower and lower value, which indicated that the EP/TDB composites had better fire safety compared to pure EP. Furthermore, the decrease of av-EHC values showed TDB endowed pure EP with good flame retardancy in the gas phase.

The data of char residue were also collated in Table 5, from which we can see that the residue of pure EP was $5.23 \%$, while the residue of $\mathrm{EP} / 10 \mathrm{wt} \% \mathrm{TDB}$ was $30.37 \%$, which increased almost five times than that of pure EP. The above results proved that TDB was a superior char forming agent, as well as an excellent flame retardant. 


\subsection{Analysis of char residue after the cone calorimeter test}

The char residue can reflect the thermal stability and flame retardancy of the material; therefore, different analysis methods, such as SEM, Raman spectroscopy, and FTIR spectroscopy, were carried out to analyze the char residue of pure EP and EP/TDB composites. The digital photos of char residue for pure $\mathrm{EP}$ and EP/TDB composites after the cone calorimeter test were shown in Figure 9. From the top sight, the char residue of pure EP was broken and fragile, while the complete carbon residues existed in all EP/TDB composites' images. From the side sight, there left a little residue char in pure EP, while EP/TDB composites' char residue were intumescent and hard. It was because of the appearance of the intumescent char residue, the exchange of heat and oxygen was restrained, as well as the diffusion of the flammable gas was astricted, thereby the fire resistance of EP/TDB composites was enhanced [29].

The SEM images of char residue were presented in Figure 10. As shown in Figure 10a, 10a', there were plentiful holes and cracks on the interior char layer, as well as plenty of cracks on the exterior char layer, which indicated that the broken char layer of pure EP failed to protect the matrix from further burning. Figure 10b-10d showed the SEM images of the interior char layer for EP/TDB composites, on which the broken bubbles and little cracks appeared, which

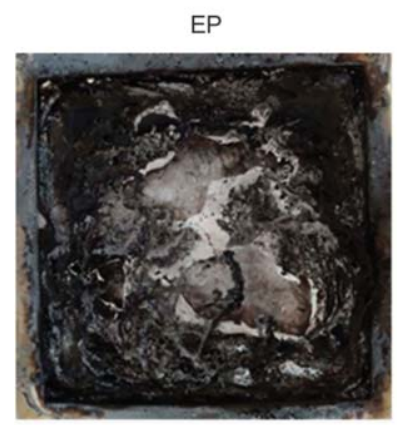

a)

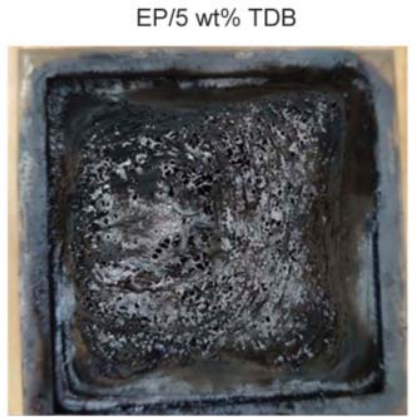

b)

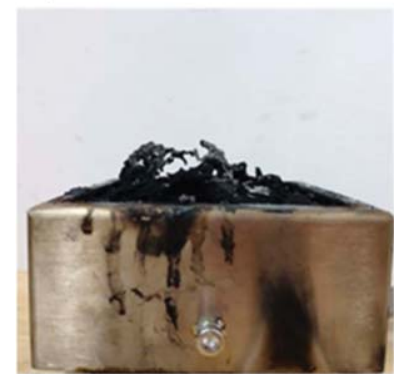

a')

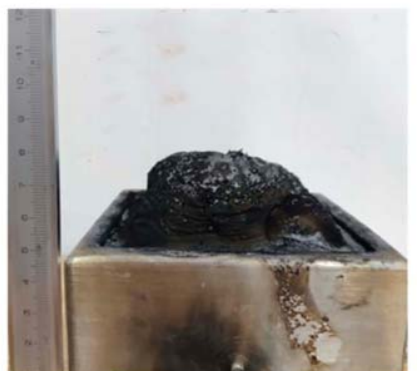

b') ascribed to the generation of noncombustible gases, and the noncombustible gases were beneficial to the formation of the intumescent char residue. Moreover, as shown in Figure 10b'-10d', owing to the incorporation of TDB, the exterior char layer was continuous and compact, this kind of char layer can act as the barrier to improve the flame retardance of condensed phase.

In order to further explore the construction of the char residue, Raman spectroscopy was adopted. Figure 11 exhibited the Raman spectra of the carbon residue for pure $\mathrm{EP}$ and $\mathrm{EP} / 10 \mathrm{wt} \% \mathrm{TDB}$ thermoset after the cone calorimeter test. There were two peaks existed in Raman spectra, the peak at $1360 \mathrm{~cm}^{-1}$ (D band) belonged to the disordered graphite or glassy carbons, while the peak at $1595 \mathrm{~cm}^{-1}$ (G band) pertained to the graphite construction. In general, the integrated intensity ratio of $\mathrm{D}$ band to $\mathrm{G}$ band $\left(I_{\mathrm{D}} / I_{\mathrm{G}}\right)$ can be utilized to estimate the degree of graphitization for char residue [45]. The lower the value of $I_{\mathrm{D}} / I_{\mathrm{G}}$ was, the higher the degree of graphitization was. As shown in Figure 11 , the $I_{\mathrm{D}} / I_{\mathrm{G}}$ value of pure EP was 2.72 , while that of $\mathrm{EP} / 10 \mathrm{wt} \% \mathrm{TDB}$ decreased to 1.97, which indicates the higher graphitized degree of char residue for EP/10 wt $\%$ TDB. The result confirmed that owing to the addition of TDB, the EP/TDB thermosets can form the compact char residue, which was in accordance with the result obtain from SEM.

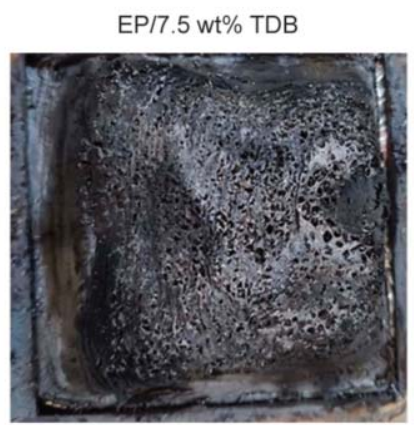

c)

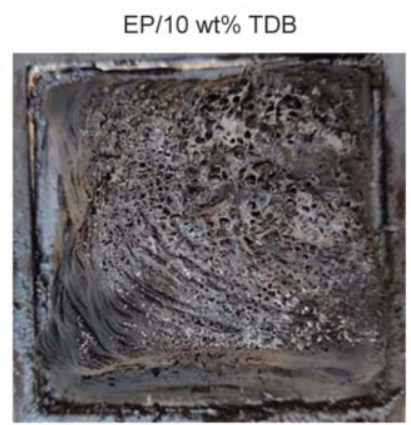

d)

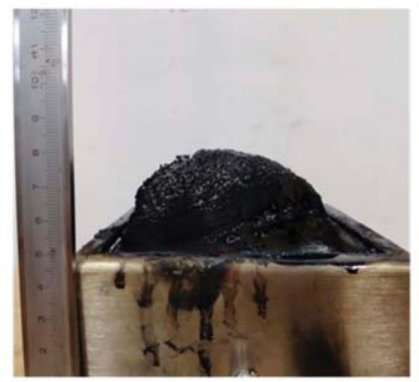

c')

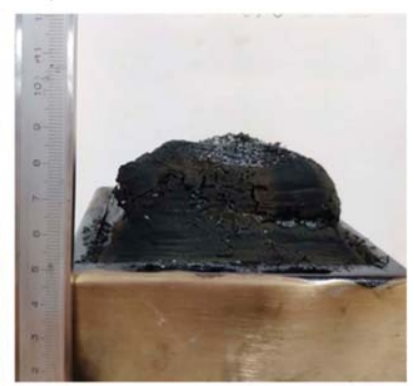

d')

Figure 9. Digital photos of the char residue from the cone calorimeter test. 

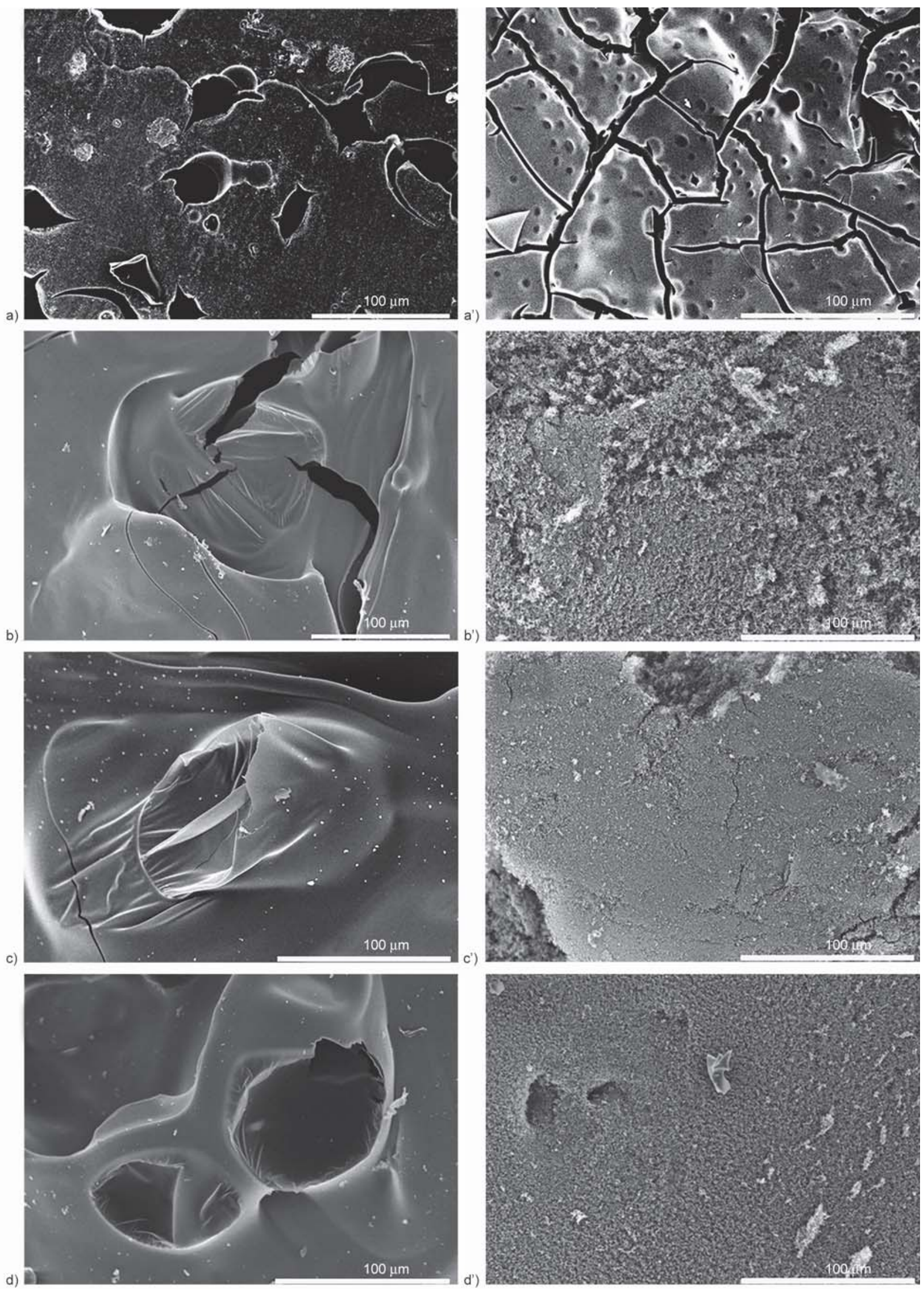

Figure 10. SEM images of the char residue after cone calorimeter test: interior morphology of pure EP (a), EP/5 wt $\%$ TDB (b), EP/7.5 wt\% TDB (c) and EP/10 wt \% TDB (d); exterior morphology of pure EP (a'), EP/5 wt $\%$ TDB (b'), EP/7.5 wt\% TDB (c') and EP/10 wt\% TDB (d'). 

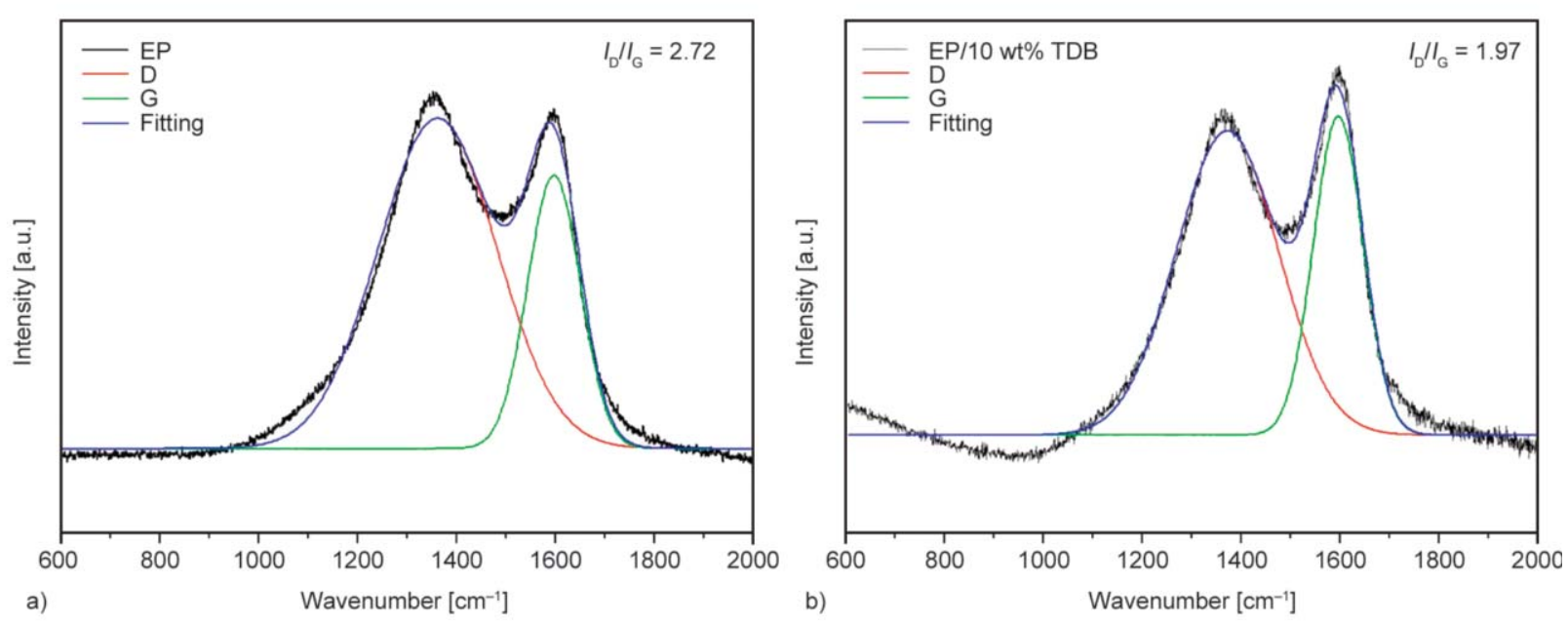

Figure 11. Raman spectra of char residues for pure EP (a) and EP/10 wt\% TDB (b).

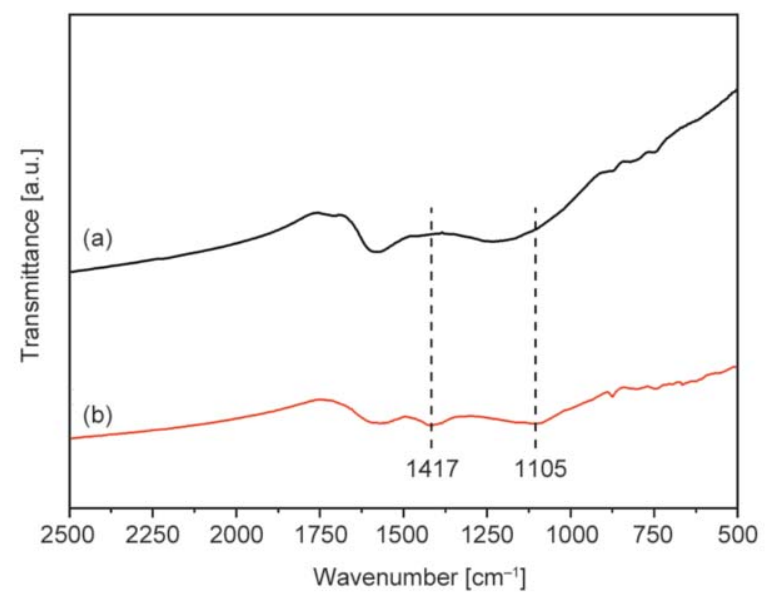

Figure 12. FTIR spectra of char residues for pure EP (a) and $\mathrm{EP} / 10 \mathrm{wt} \% \mathrm{TDB}(\mathrm{b})$, respectively.

In order to study the chemical composition of the char residue after the cone calorimeter test, FTIR spectra were used to analyze the char residues of pure EP and EP/10 wt \% TDB composite, and the corresponding curves were presented in Figure 12. As shown in Figure 12, there appeared two new absorption peaks in EP/10 wt\% TDB composite compared with pure EP, the characteristic absorption peaks at 1417 and $1105 \mathrm{~cm}^{-1}$ corresponding to $\mathrm{B}-\mathrm{O}-\mathrm{C}$ and $\mathrm{P}-\mathrm{O}-\mathrm{C}$, respectively [29]. These results indicated that the compounds which contained phosphorus and boron derived from the decomposition of TDB could facilitate the formation of a compact and stable char layer, which exerted the flame retardance in the condensed phase.

\subsection{Analysis of pyrolysis products}

From the chemical structure of TDB, we could speculate that TDB has a positive effect in the gas phase; hence, Py-GC/MS was carried out to investigate the volatile products of TDB, so as to explore the flameretardant effect in the gas phase. The total ion chromatogram of TDB was shown in Figure 13a, and the MS spectra at $500^{\circ} \mathrm{C}$ at 9.6 and 23.3 min exhibited in Figure 13b and Figure 13c, respectively, which contained the typical fragment flows with characteristic ionic peaks, were picked to research the pyrolysis route of TDB. The possible pyrolysis route of TDB was shown in Figure 14. From the result of the FTIR spectra of char residues, it was known that the boron-containing fragments mainly remained in the condensed phase; therefore, the pyrolysis products of TDB can be divided into two varieties, diphenyl phosphate fragment and tri-ethylethyl-triazine-trione fragment, which can further disintegrate into smaller decomposition fragments. As can be seen in Figure 14, the triazine-trione structure converted into tri-ethylethyl-triazine-trione fragment $(\mathrm{m} / \mathrm{z}=207)$, which can further split into nitrogen-containing compounds $(\mathrm{m} / \mathrm{z}=69,43)$ and active allyl radical $(\mathrm{m} / \mathrm{z}=$ $41)$, with the continued degradation, the ultimate product--cyclopropylium $(\mathrm{m} / \mathrm{z}=39)$ was obtained. In addition, diphenyl phosphate fragment $(\mathrm{m} / \mathrm{z}=249)$ was separated from TDB, which can further convert into phosphorous-containing fragment $(\mathrm{m} / \mathrm{z}=157)$, phenoxyl radical $(m / z=93)$, phenol $(m / z=94), \cdot \mathrm{PO}_{2}$ $(m / z=63)$ and $\mathrm{HPO}_{2}(m / z=64)$ free radicals. Based on the above pyrolysis route, the flame-retardant effect of TDB in gaseous phase can be explained as follows: on the one hand, the nitrogen-containing compounds generated from triazine-trione structure during fire can dilute the oxygen concentration around the flame and the flammable gases released from the EP matrix, as well as take away part of heat. On the other hand, the phosphorus-containing free radicals 
derived from diphenyl phosphate fragment can cap- free radical chain reaction, leading to the weak burnture the $\cdot \mathrm{H}$ and $\bullet \mathrm{OH}$ free radicals, terminating the ing intensity.
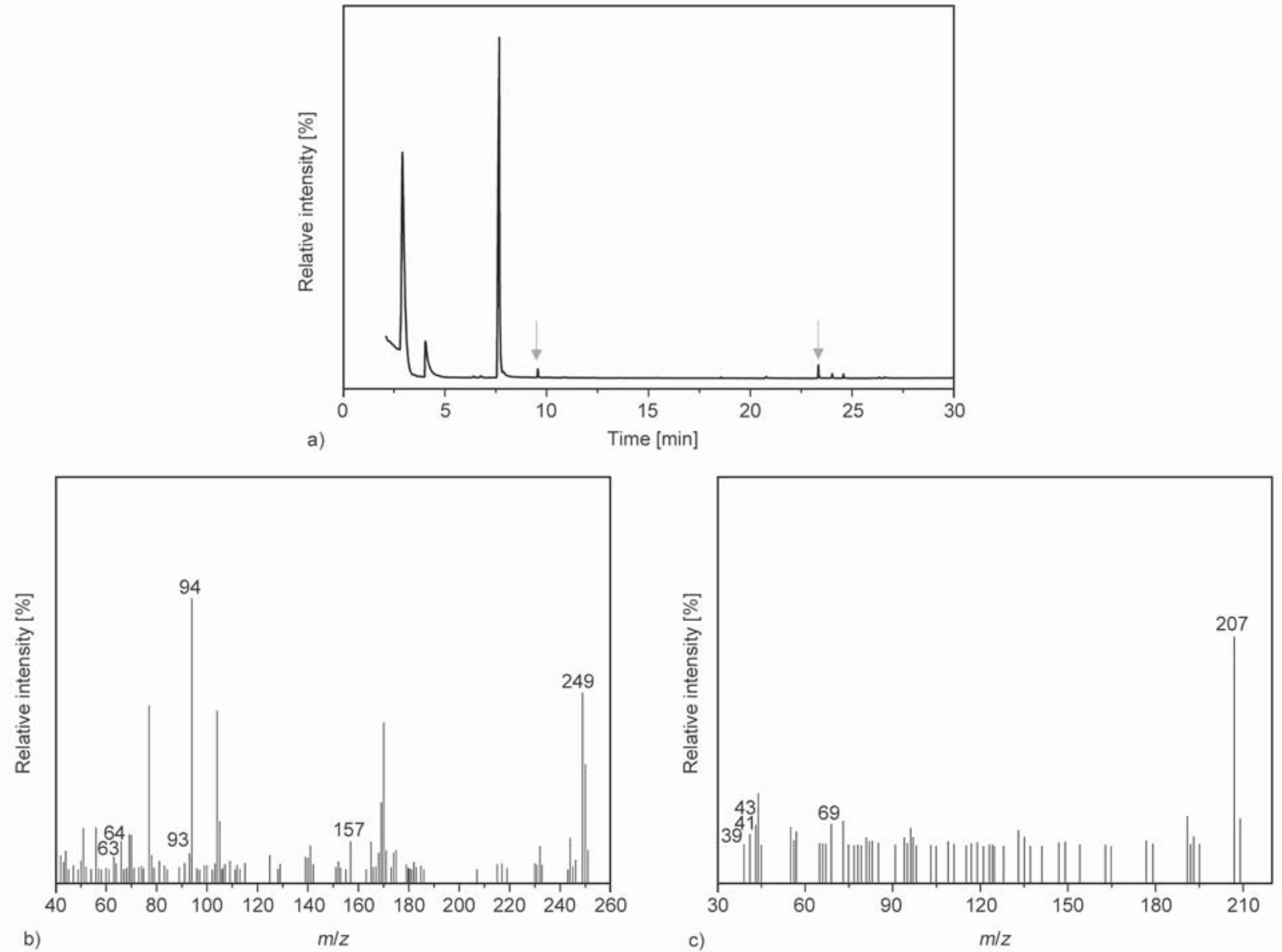

Figure 13. Total ion chromatogram (a) and typical MS spectrum of TDB at $9.6 \mathrm{~min}$ (b) and $23.3 \mathrm{~min}$ (c).

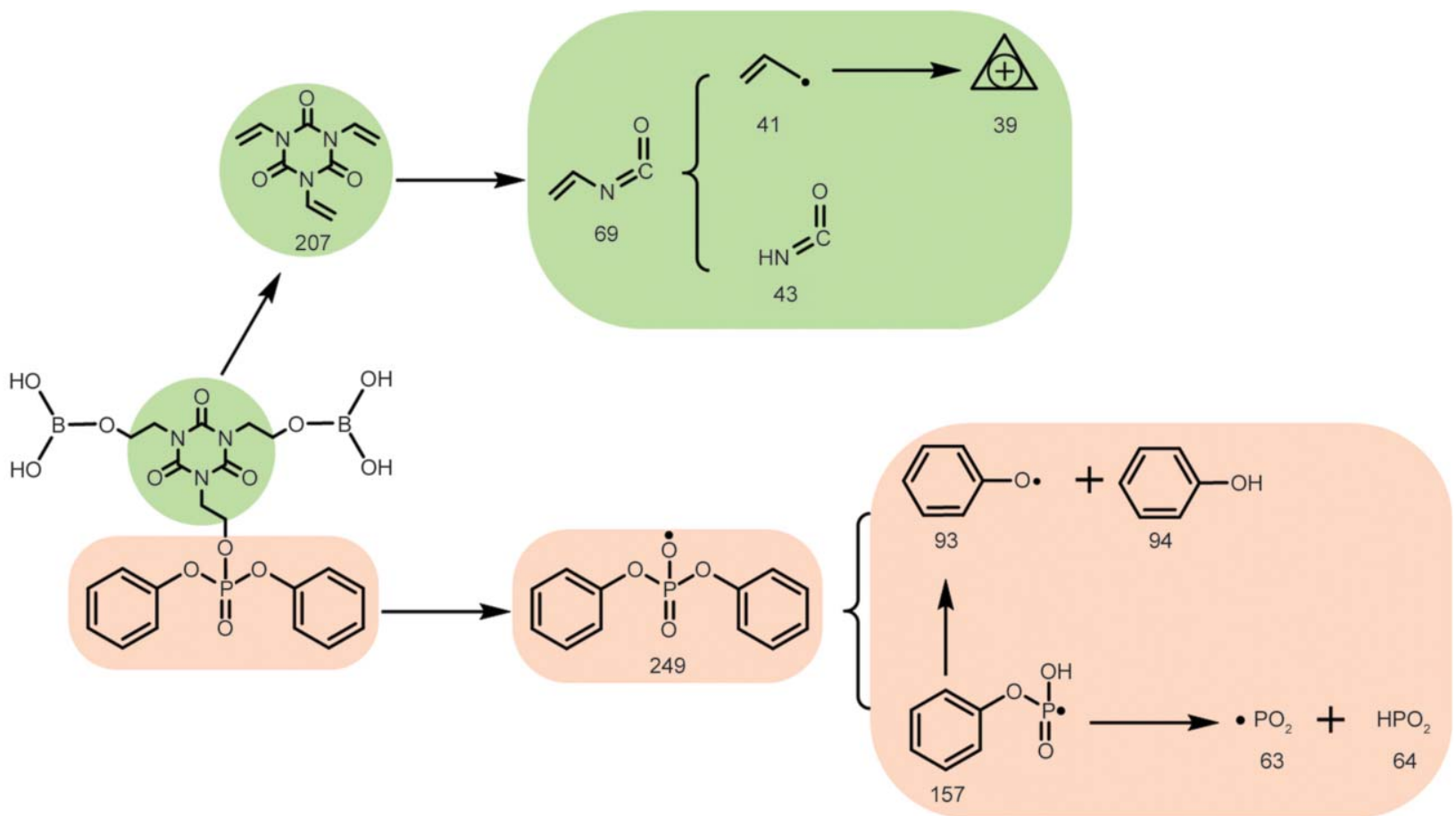

Figure 14. The possible pyrolysis route of TDB. 


\section{Conclusions}

In this work, a novel flame retardant TDB containing boron and phosphorus, based on triazine-trione structure was successfully synthesized, via substitution and esterification reaction between THEIC, DPCP, and boric acid, and then blended into DGEBA to prepare flame-retardant composites. The maximum added amount was controlled to be about $10 \mathrm{wt} \%$, accompanied by the best overall performance. With the increasing content of TDB, the $T_{\mathrm{g}}, T_{5 \%}$ and $T_{\max }$ values of EP samples were gradually decreased, while the char yields were increased. The incorporation of TDB can enhance the flame retardancy of EP, the LOI value of EP/10 wt $\%$ TDB composite was $27.5 \%$, and the UL-94 rating reached to V-0. The pk-HRR, THR, pk-SPR, and TSP of EP/10wt\% TDB thermoset were decreased by $52.66,30.43,30.43$, and $29.15 \%$, respectively, compared with pure EP. The good flame retardancy of EP thermosets can be attributed to the positive effect of TDB both in the gas phase and condensed phases. On the one hand, the non-flammable gases and phosphorus-containing free radicals from triazine-trione and DPCP structure can develop the flame retardancy in the gas phase; on the other hand, on account of the existence of triazinetrione structure and phosphorus/boron elements, the intumescent and compact phosphorus/boron-rich char layer was formed, which can act as a perfect barrier to prevent the exchange of heat and oxygen.

\section{Acknowledgements}

This work was financially supported by the National Natural Science Foundation of China (51573144), the Natural Science Foundation of Hubei Province (ZRMS2019001284), and the Fundamental Research Funds for the Central Universities (WUT:2019III164CG).

\section{References}

[1] Wan J., Gan B., Li C., Molina-Aldareguia J., Kalali E. N., Wang X., Wang D-Y.: A sustainable, eugenol-derived epoxy resin with high biobased content, modulus, hardness and low flammability: Synthesis, curing kinetics and structure-property relationship. Chemical Engineering Journal, 284, 1080-1093 (2016).

https://doi.org/10.1016/j.cej.2015.09.031

[2] Dogan M., Murat Unlu S.: Flame retardant effect of boron compounds on red phosphorus containing epoxy resins. Polymer Degradation and Stability, 99, 12-17 (2014).

https://doi.org/10.1016/j.polymdegradstab.2013.12.017
[3] Qu L., Zhang C., Li P., Dai X., Xu T., Sui Y., Gu J., Dou Y.: Improved thermal properties of epoxy resin modified with polymethyl methacrylate-microencapsulated phosphorus-nitrogen-containing flame retardant. RSC Advances, 8, 29816-29829 (2018).

https://doi.org/10.1039/c8ra05911j

[4] Toldy A., Szolnoki B., Marosi G.: Flame retardancy of fibre-reinforced epoxy resin composites for aerospace applications. Polymer Degradation and Stability, 96, 371-376 (2011).

https://doi.org/10.1016/j.polymdegradstab.2010.03.021

[5] He D., Zhao C., Gou H., Li Y., Xiang D.: Flame retardancy and toughening properties of epoxy composites containing ammonium polyphosphate microcapsules and expanded graphite. High Performance Polymers, 30, 1247-1259 (2017). https://doi.org/10.1177/0954008317747952

[6] Li A., Xu W., Chen R., Liu Y., Li W.: Fabrication of zeolitic imidazolate frameworks on layered double hydroxide nanosheets to improve the fire safety of epoxy resin. Composites Part A: Applied Science and Manufacturing, 112, 558-571 (2018).

https://doi.org/10.1016/j.compositesa.2018.07.001

[7] Wang S., Xin F., Chen Y., Qian L., Chen Y.: Phosphorus-nitrogen containing polymer wrapped carbon nanoubes and their flame-retardant effect on epoxy resin. Polymer Degradation and Stability, 129, 133-141 (2016).

https://doi.org/10.1016/j.polymdegradstab.2016.04.011

[8] Xu W., Zhang B., Wang X., Wang G., Ding D.: The flame retardancy and smoke suppression effect of a hybrid containing $\mathrm{CuMOO}_{4}$ modified reduced graphene oxide/layered double hydroxide on epoxy resin. Journal of Hazardous Materials, 343, 364-375 (2018). https://doi.org/10.1016/j.jhazmat.2017.09.057

[9] Tao X., Duan H., Dong W., Wang X., Yang S.: Synthesis of an acrylate constructed by phosphaphenanthrene and triazine-trione and its application in intrinsic flame retardant vinyl ester resin. Polymer Degradation and Stability, 154, 285-294 (2018). https://doi.org/10.1016/j.polymdegradstab.2018.06.015

[10] Jin S., Qian L., Qiu Y., Chen Y., Xin F.: High-efficiency flame retardant behavior of bi-dopo compound with hydroxyl group on epoxy resin. Polymer Degradation and Stability, 166, 344-352 (2019). https://doi.org/10.1016/j.polymdegradstab.2019.06.024

[11] Battig A., Markwart J. C., Wurm F. R., Schartel B.: Matrix matters: Hyperbranched flame retardants in aliphatic and aromatic epoxy resins. Polymer Degradation and Stability, 170, 108986/1-108986/15 (2019). https://doi.org/10.1016/j.polymdegradstab.2019.108986

[12] Zhu Z-M., Shang K., Wang L-X., Wang J-S.: Synthesis of an effective bio-based flame-retardant curing agent and its application in epoxy resin: Curing behavior, thermal stability and flame retardancy. Polymer Degradation and Stability, 167, 179-188 (2019). https://doi.org/10.1016/j.polymdegradstab.2019.07.005 
[13] Deng P., Shi Y., Liu Y., Liu Y., Wang Q.: Solidifying process and flame retardancy of epoxy resin cured with boron-containing phenolic resin. Applied Surface Science, 427, 894-904 (2018).

https://doi.org/10.1016/j.apsusc.2017.07.278

[14] Ahmad F., Zulkurnain E. S. B., Ullah S., Amir N.: Effects of nano-sized boron nitride on thermal decomposition and water resistance behaviour of epoxy-based intumescent coating. Journal of Analytical and Applied Pyrolysis, 132, 171-183 (2018).

https://doi.org/10.1016/j.jaap.2018.03.002

[15] Unlu S. M., Dogan S. D., Dogan M.: Comparative study of boron compounds and aluminum trihydroxide as flame retardant additives in epoxy resin. Polymers for Advanced Technologies, 25, 769-776 (2014). https://doi.org/10.1002/pat.3274

[16] Huang S., Hou X., Li J., Tian X., Yu Q., Wang Z.: A novel curing agent based on diphenylphosphine oxide for flame-retardant epoxy resin. High Performance Polymers, 30, 1229-1239 (2017). https://doi.org/10.1177/0954008317745957

[17] Li C., Fan H., Aziz T., Bittencourt C., Wu L., Wang D-Y., Dubois P.: Biobased epoxy resin with low electrical permissivity and flame retardancy: From environmental friendly high-throughput synthesis to properties. ACS Sustainable Chemistry and Engineering, 6, 8856-8867 (2018). https://doi.org/10.1021/acssuschemeng.8b01212

[18] Sonnier R., Dumazert L., Livi S., Nguyen T. K. L., Duchet-Rumeau J., Vahabi H., Laheurte P.: Flame retardancy of phosphorus-containing ionic liquid based epoxy networks. Polymer Degradation and Stability, 134, 186-193 (2016).

https://doi.org/10.1016/j.polymdegradstab.2016.10.009

[19] Alongi J., Malucelli G.: Cotton fabrics treated with novel oxidic phases acting as effective smoke suppressants. Carbohydrate Polymers, 90, 251-260 (2012). https://doi.org/10.1016/j.carbpol.2012.05.032

[20] Oualha M. A., Amdouni N., Laoutid F.: Synergistic flame-retardant effect between calcium hydroxide and zinc borate in ethylene-vinyl acetate copolymer (EVA). Polymer Degradation and Stability, 144, 315-324 (2017). https://doi.org/10.1016/j.polymdegradstab.2017.08.032

[21] Shao Z-B., Zhang M-X., Li Y., Han Y., Ren L., Deng C.: A novel multi-functional polymeric curing agent: Synthesis, characterization, and its epoxy resin with simultaneous excellent flame retardance and transparency. Chemical Engineering Journal, 345, 471-482 (2018). https://doi.org/10.1016/j.cej.2018.03.142

[22] Xu Y-J., Chen L., Rao W-H., Qi M., Guo D-M., Liao W., Wang Y-Z.: Latent curing epoxy system with excellent thermal stability, flame retardance and dielectric property. Chemical Engineering Journal, 347, 223-232 (2018).

https://doi.org/10.1016/j.cej.2018.04.097
[23] Xu Y-J., Wang J., Tan Y., Qi M., Chen L., Wang Y-Z.: A novel and feasible approach for one-pack flame-retardant epoxy resin with long pot life and fast curing. Chemical Engineering Journal, 337, 30-39 (2018). https://doi.org/10.1016/j.cej.2017.12.086

[24] Zhou Y., Feng J., Peng H., Qu H., Hao J.: Catalytic pyrolysis and flame retardancy of epoxy resins with solid acid boron phosphate. Polymer Degradation and Stability, 110, 395-404 (2014).

https://doi.org/10.1016/j.polymdegradstab.2014.10.009

[25] Tang S., Qian L., Qiu Y., Dong Y.: High-performance flame retardant epoxy resin based on a bi-group molecule containing phosphaphenanthrene and borate groups. Polymer Degradation and Stability, 153, 210-219 (2018). https://doi.org/10.1016/j.polymdegradstab.2018.04.037

[26] Zhang T., Liu W., Wang M., Liu P., Pan Y., Liu D.: Synergistic effect of an aromatic boronic acid derivative and magnesium hydroxide on the flame retardancy of epoxy resin. Polymer Degradation and Stability, 130, 257-263 (2016). https://doi.org/10.1016/j.polymdegradstab.2016.06.011

[27] Kawahara T., Yuuki A., Hashimoto K., Fujiki K., Yamauchi T., Tsubokawa N.: Immobilization of flameretardant onto silica nanoparticle surface and properties of epoxy resin filled with the flame-retardant-immobilized silica (2). Reactive and Functional Polymers, 73, 613-618 (2013).

https://doi.org/10.1016/j.reactfunctpolym.2013.01.001

[28] Qian X., Song L., Bihe Y., Yu B., Shi Y., Hu Y., Yuen R. K. K.: Organic/inorganic flame retardants containing phosphorus, nitrogen and silicon: Preparation and their performance on the flame retardancy of epoxy resins as a novel intumescent flame retardant system. Materials Chemistry and Physics, 143, 1243-1252 (2014). https://doi.org/10.1016/j.matchemphys.2013.11.029

[29] Yang S., Zhang Q., Hu Y.: Synthesis of a novel flame retardant containing phosphorus, nitrogen and boron and its application in flame-retardant epoxy resin. Polymer Degradation and Stability, 133, 358-366 (2016). https://doi.org/10.1016/j.polymdegradstab.2016.09.023

[30] Zhao B., Liang W-J., Wang J-S., Li F., Liu Y-Q.: Synthesis of a novel bridged-cyclotriphosphazene flame retardant and its application in epoxy resin. Polymer Degradation and Stability, 133, 162-173 (2016). https://doi.org/10.1016/j.polymdegradstab.2016.08.013

[31] Zhou L., Zhang G., Li J., Jing Z., Qin J., Feng Y.: The flame retardancy and thermal stability properties of flame-retarded epoxy resins based on $\alpha$-hydroxyphosphonate cyclotriphosphazene. Journal of Thermal Analysis and Calorimetry, 129, 1667-1678 (2017). https://doi.org/10.1007/s10973-017-6319-Z

[32] Liang W-J., Zhao B., Zhang C-Y., Jian R-K., Liu D-Y., Liu Y-Q.: Enhanced flame retardancy of DGEBA epoxy resin with a novel bisphenol-A bridged cyclotriphosphazene. Polymer Degradation and Stability, 144, 292303 (2017).

https://doi.org/10.1016/j.polymdegradstab.2017.08.027 
[33] Wang P., Chen L., Xiao H.: Flame retardant effect and mechanism of a novel dopo based tetrazole derivative on epoxy resin. Journal of Analytical and Applied Pyrolysis, 139, 104-113 (2019).

https://doi.org/10.1016/j.jaap.2019.01.015

[34] Shen D., Xu Y-J., Long J-W., Shi X-H., Chen L., Wang Y-Z.: Epoxy resin flame-retarded via a novel melamineorganophosphinic acid salt: Thermal stability, flame retardance and pyrolysis behavior. Journal of Analytical and Applied Pyrolysis, 128, 54-63 (2017).

https://doi.org/10.1016/j.jaap.2017.10.025

[35] Huo S., Wang J., Yang S., Wang J., Zhang B., Zhang B., Chen X., Tang Y.: Synthesis of a novel phosphorus-nitrogen type flame retardant composed of maleimide, triazine-trione, and phosphaphenanthrene and its flame retardant effect on epoxy resin. Polymer Degradation and Stability, 131, 106-113 (2016).

https://doi.org/10.1016/j.polymdegradstab.2016.07.013

[36] Wu H., Zeng B., Chen J., Wu T., Li Y., Liu Y., Dai L.: An intramolecular hybrid of metal polyhedral oligomeric silsesquioxanes with special titanium-embedded cage structure and flame retardant functionality. Chemical Engineering Journal, 374, 1304-1316 (2019). https://doi.org/10.1016/j.cej.2019.06.027

[37] Schmidt C., Ciesielski M., Greiner L., Döring M.: Novel organophosphorus flame retardants and their synergistic application in novolac epoxy resin. Polymer Degradation and Stability, 158, 190-201 (2018).

https://doi.org/10.1016/j.polymdegradstab.2018.09.001

[38] Khanal S., Zhang W., Ahmed S., Ali M., Xu S.: Effects of intumescent flame retardant system consisting of tris (2-hydroxyethyl) isocyanurate and ammonium polyphosphate on the flame retardant properties of highdensity polyethylene composites. Composites Part A: Applied Science and Manufacturing, 112, 444-451 (2018).

https://doi.org/10.1016/j.compositesa.2018.06.030
[39] Tang S., Qian L., Liu X., Dong Y.: Gas-phase flame-retardant effects of a bi-group compound based on phosphaphenanthrene and triazine-trione groups in epoxy resin. Polymer Degradation and Stability, 133, 350-357 (2016).

https://doi.org/10.1016/j.polymdegradstab.2016.09.014

[40] Huo S., Wang J., Yang S., Li C., Wang X., Cai H.: Synthesis of a dopo-containing imidazole curing agent and its application in reactive flame retarded epoxy resin. Polymer Degradation and Stability, 159, 79-89 (2019). https://doi.org/10.1016/j.polymdegradstab.2018.11.021

[41] Chen R., Hu K., Tang H., Wang J., Zhu F., Zhou H.: A novel flame retardant derived from dopo and piperazine and its application in epoxy resin: Flame retardance, thermal stability and pyrolysis behavior. Polymer Degradation and Stability, 166, 334-343 (2019). https://doi.org/10.1016/j.polymdegradstab.2019.06.011

[42] Kim Y-O., Cho J., Yeo H., Lee B. W., Moon B. J., Ha Y-M., Jo Y. R., Jung Y. C.: Flame retardant epoxy derived from tannic acid as biobased hardener. ACS Sustainable Chemistry and Engineering, 7, 3858-3865 (2019). https://doi.org/10.1021/acssuschemeng.8b04851

[43] Zhao D., Wang J., Wang X-L., Wang Y-Z.: Highly thermostable and durably flame-retardant unsaturated polyester modified by a novel polymeric flame retardant containing Schiff base and spirocyclic structures. Chemical Engineering Journal, 344, 419-430 (2018). https://doi.org/10.1016/j.cej.2018.03.102

[44] Xu W., Wang X., Wu Y., Li W., Chen C.: Functionalized graphene with Co-ZIF adsorbed borate ions as an effective flame retardant and smoke suppression agent for epoxy resin. Journal of Hazardous Materials, 363, 138151 (2019). https://doi.org/10.1016/j.jhazmat.2018.09.086

[45] Wu J-N., Chen L., Fu T., Zhao H-B., Guo D-M., Wang X-L., Wang Y-Z.: New application for aromatic Schiff base: High efficient flame-retardant and anti-dripping action for polyesters. Chemical Engineering Journal, 336, 622-632 (2018).

https://doi.org/10.1016/j.cej.2017.12.047 